\title{
Nutritive Value and Improving Palatability of Bitter Melon (Momordica charantia L.)
}

\author{
Abo Taleb, Hasnaa M.; Hanan A. Abd El Aziz; Azza Kamal El Deen Abd El Hameed \\ Department of Horticultural Crops Tech. Res., Food Technology Research Institute, Agricultural Research \\ Center, Giza, Egypt
}

Received: $6 / 2 / 2018$

\begin{abstract}
Bitter melon (Carvilla), is a popular traditional medicinal vegetable in tropical and subtropical countries. A larger population of people does not like the bitterness of this fruit and processing into beverages is believed to increase its palatability and acceptability. The aim of this work was to determine the chemical composition of the carvilla fruits and as a trail to remove the bitter taste to use it as a food component in the preparation of carvilla drink with tea as well as spearmint. The obtained results indicated that the fresh and dry (with bitterness T1 and without bitterness T2) carvilla fruits had high levels of ash and protein contents (8.54, 8.32 and 7.92\% and 13.21, 13.42 and $13.14 \%$, respectively). The anti-oxidant activity of fresh and dry carvilla fruits (T1) were higher than carvilla fruits (T2). Carvilla is also a good source of mineral elements, especially potassium, calcium, magnesium, iron and zinc. Sugars such as maltose, sucrose, arbinose, fructose, stachyose, glucuronic and galcturonic represented in high ratios of fresh carvilla while decreased after soaking and drying. e-vanillic, pyrogalol and benzoic acid were the major phenolic compounds, whereas, rosemarynic, quercetrine, spiridine and acacetin were the predominant of flavonoid compounds, which decreased after soaking and drying. Vitamins B3, B6, B12 and $\mathrm{K}$ were the predominant vitamins found in carvilla fruits. The $\mathrm{IC}_{50}$ of fresh and dried bitter melon extract showed high active as anti-cancer for lung cell while dried bitter melon free from bitterness did not show any effect. The results of sensory properties showed that the addition of dry and after removal of bitterness carvilla powder in the mentioned ratios (1:3) gave the highest scores, improving the taste grades of the drinks and were preferred by the consumers.
\end{abstract}

Keywords: Bitter melon, carvilla fruits, nutritional value, antioxidants, phenols, flavonoids, sugars, vitamins

\section{INTRODUCTION}

Bitter melon or bitter gourd (Momordica charantia L.), which belongs to the family cucurbitaceae and momordica genus. Bitter melon is used for human consumption all over the world in different forms such as a vegetable and / or medicine (Verma, 2015). Immature fruits of bitter gourd could be prepared in many ways such as frying or cooking as curries, whereas, fruits can be dehydrated, pickled or canned. Also, blanched or soaked in salt water before cooking to reduce the bitter taste (Krawinkel and Keding, 2014). Incorporating bitter foods in commonly consumed food dishes can mask the bitter taste of bitter gourd (Snee et al., 2011).

It is found to be highly nutritive with high levels of protein, minerals and vitamins, (Kubola and Siriamarnpun, 2008). The extract had the highest value of antioxidant activity and that gallic acid was the predominant phenolic compound (Kubola and Siriamarnpun, 2008). Islam et al. (2011) determined the chemical composition of four varieties of bitter mellon and showed that, the moisture contents ranged from 92.4 to $93.5 \%$ and protein contents of $8.4-9.8 \%$. Bitter melon is a good source for phenolic compounds, high antioxidant, anti-mutagenic activities and had a biological activity that may be applied in many food systems to enhance food values and special nutritional qualities (Shahidul et al., 2011). Bitter melon phenolic extracts contain natural antioxidant substances and could be used as antioxidant agents in suitable food products (Basch et al., 2003; Zhu et al., 2012). Drewnowski and Gomez-Carneros (2000) found that medicinal value of bitter melon has been attributed to its

*Corresponding author e-mail: dr.hasnaa_m@yahoo.com high antioxidant properties due to phenols, flavonoids, isoflavones, terpenes, anthroquinones, and glucosinolates, all of which confer a bitter taste. Removal of active bitter components, through a variety of debittering processes as well as selective breeding can result in loss of possible health benefits.

Kubola and Siriamornpun (2011) investigated that, ferrulic and $\rho$-hydroxy benzoic acids were most evident in bitter melon pulp. Myricetin was the only flavonoid found in all fractions of fruits. Apigenin was the most predominant flavonoid in pulp but the highest antioxidant activities of pulp extracts were at immature stage. The total phenolic and total flavonoids contents in pulp decreased during the fruit development stage and subsequently displayed lower antioxidant capacity. Horax et al. (2010) extracted phenolic compounds from (fleshy portion) of bitter melon harvested at three maturation stages (immature, mature, and ripe) and found that the main phenolic constituents were catechin, gallic acid, gneissic acid, chlorogenic acid, and epicatechin. Sheel and Sruthi (2014) designed to prepare ready-to-serve (RTS) beverages by blending extracts of bitter melon with fruit extracts like mosambi and lemon. These blends had higher values of energy, carbohydrate, vitamin $\mathrm{C}$, protein and iron. The blends had good sensory attributes and shelf life up to a period of 45 days.

Sheng et al. (2006) reported that drying method of bitter melon was preferred because of some advantages like it reduced mass (bulk) and lower the cost of packaging and storage. On the other hand, Kuri et al. (1991) revealed that bitter gourd develops rubbery texture and become brown in addition to that it also 
loses some of its bitterness, ascorbic acid and chlorophyll during drying. Superfine grinding and lyophilization are helpful for improving extraction of proteins, polysaccharides and other bioactive components such as total phenols, flavonoids and saponins from bitter melon. Bitter melon lyophilized superfine grinding powder had higher total polyphenols of $10.03 \mathrm{mg} / \mathrm{g}$ and total flavonoids of $5.27 \mathrm{mg} / \mathrm{g}$ compared with its hot air drying superfine grinding powder.

Dandawate et al. (2016) revealed that Momordica charantia, commonly known for their biological activities used in traditional system of medicines. All parts of the plant, including the fruit, are commonly consumed and cooked with different vegetables. Beverages or drinks are considered to be an excellent medium for the supplementation and nutraceutical compounds for enactment. Beverages from fruits and vegetables are important in human diet. People of all groups consume them to quench the thirst and as health food (Khan and Anderson, 2003).

Therefore, the aim of this work was to determine chemical composition and bioactive compounds. Also a trial to remove the bitter taste from carvilla fruits and utilize its powder for making carvilla drink as an untraditional functional drink.

\section{MATERIALS AND METHODS}

Bitter melon or bitter gourd (Momordica charantia L.), was obtained from Faculty of Agriculture, Mansoura University, Mansoura Governorate, Egypt. Black tea (Lipton) imported from Kenia and packed in Egypt by Unilever Mashreq, Tea Company County origin. Spearmint powder was purchased from ISIS company for food processing, Egypt.

All chemicals and reagents used in the present study were of analytical grade and purchased from AlGomhouria Company. Chemicals used in HPLC methods were of HPLC grade and purchased from Sigma Company.

\section{METHODS}

\section{Preparation of bitter melon powder}

Fresh mature bitter melon fruits (Long green) were washed with tap water, cut into thin slices with stainless steel knife approximately $0.25 \mathrm{~cm}$ and removed seeds then divided as follows:

\section{Fresh bitter melon had not any treatment (control).}

Drying of bitter melon (T1): Fresh bitter melon was dried in a hot air oven at $\left(55 \mathrm{C}^{\circ} \pm 5\right)$ until reaching to constant weight then grinded using an electrical mill, packed in polyethylene pouches then stored at $4 \mathrm{C}^{\circ}$ for analysis.

Soaked and dried bitter melon (T2): Fresh bitter melon was soaked in $5 \%$ salt solution at $90 \mathrm{C}^{\circ}$ for 2 min., washed with cold water for $5 \mathrm{~min}$. (to remove the bitterness) as described by Kulkarni et al. (2005), then was dried as T1.
Formulation of bitter melon powder with black tea or spearmint beverage

The powder of bitter melon was used to make eleven samples of drinks from bitter melon (with/without bitterness), black tea and spearmint powder as follows:

Bitter melon powder only (control)

1 - Bitter melon powder + black tea or spearmint $(1+1)$

2- Bitter melon powder + black tea or spearmint $(1+2)$

3 - Bitter melon powder + black tea or spearmint $(1+3)$

4- Bitter melon powder + black tea or spearmint $(2+1)$

5 - Bitter melon powder + black tea or spearmint $(3+1)$

The drinks were prepared according to the methods of RSC (2003).

\section{Physio-chemical analysis}

Moisture, ash, crude protein, crude fiber, total soluble solids (TSS), total acidity contents and $\mathrm{pH}$ value were determined according to the methods of the AOAC (2010).

Minerals contents $(\mathrm{Ca}, \mathrm{Mg}, \mathrm{Fe}$ and $\mathrm{Zn}$ ) were detected using Perkin Elmer Atomic Absorption Spectrophotometer (Model 2380, Japan), whereas, Mn and $\mathrm{K}$ were determined using Flame Photometer (model PEP7, England) as described in the AOAC (2010).

Chlorophyll A, B and total carotenoids were determined according to Raghuramulu et al. (1983).

Antioxidant activity was determined according to the method described by Alothman et al. (2009).

The sugars of fresh and dried bitter melon were fractionated and identified by HPLC (Hewllet Packared, series 1050 county origin) according to the method of Chinnici et al. (2005).

Fractionation and identification of phenolic and flavonoid compounds were performed by HPLC according to the methods described by Pascale et al. (1999) and Pirjo et al. (2000).

Vitamins B complex group of fresh and dried bitter melon were determined by HPLC according to the method of Papadoyannis et al. (1997). Vitamin A and E were also determined by HPLC as described by Pyka and Sliwiok (2001), vitamin K by Tomas et al. (2007) and vitamin $\mathrm{D}$ determined according to Gfimiz-Gracia et al. (2000).

Measurement of potential cytotoxicity by SRB assay

The potential cytotoxic activity of tested samples (fresh bitter melon and dried bitter melon T1 and T2) ethanolic extracts against of human lung carcinoma (A549) cell lines were tested in Department of Oncology, Pharmacology Unit, National Cancer Institute, Cairo, Egypt, using the Sulphodiamine - B assay (SRB) according to the method of Skehan et al. (1990).

\section{Sensory evaluation}

Organoleptic parameters, color, taste, odor, texture and overall palatability were evaluated through nine-point scale, where 9 is extremely liked and 1 extremely disliked. Trained panelists were selected from Food Tech. Res. Institute (FTRI), including both male and female members (Lee et al. (2003). 


\section{Statistical analysis}

The collected data were analyzed using SAS (version 10.0: SAS Institute Inc. Cary, NC) using one way (ANOVA) and Duncan comparisons were tested to signify differences between different samples. A level $(\mathrm{P}<0.05)$ was accepted as statistically significant. Data were expressed as means $\pm \mathrm{SD}$, according to Snedecor and Cochran (1980).

\section{RESULTS AND DISCUSSION}

The chemical composition of bitter melon (Momordica charantia) presented in Table (1). Results revealed that fresh bitter melon contained a high level of moisture $(92.84 \%)$, which decreased after drying to be 8.40 and $8.09 \%$ for $\mathrm{T} 1$ and $\mathrm{T} 2$, respectively. Protein, crude fiber and ash contents were 13.21, 1.47 and $8.54 \%$, respectively, for fresh bitter melon then, recorded, 13.42, 1.42, 8.32\% and 13.14, 1.39 and $7.92 \%$ for $\mathrm{T} 1$ and $\mathrm{T} 2$, respectively. The total soluble solids in fresh bitter melon (32.12\%) decreased to be 21.62 and $9.57 \%$ (dry weight basis) after dried for $\mathrm{T} 1$ and $\mathrm{T} 2$, respectively. The $\mathrm{pH}$ values showed clear increase after drying and soaking in water where (4.64 for fresh, 4.88 for $\mathrm{T} 1$ and 5.42 for $\mathrm{T} 2$ ). Total acidity of fresh bitter melon, $\mathrm{T} 1$ and $\mathrm{T} 2$ were $2.91,3.07$ and $1.81 \%$, respectively. These results are nearest with those obtained by Yuwai et al. (1991) who found that the values of moisture, lipids, protein and ash contents in bitter melon were 93.20, 0.78, 18.02 and 8.12\%, respectively. Gopelan et al. (1993) found that moisture, carbohydrates, proteins and fibers were 83.20, 10.60, 2.10 and $1.70 \mathrm{~g} / 100 \mathrm{~g}$, respectively. Chlorophyll A, B and total carotenoids of fresh bitter melon were found to be relatively higher than that of $\mathrm{T} 1$ and $\mathrm{T} 2$. These results indicated that drying and soaking with drying were more effective comparing to fresh bitter melon, this previous changes are related to the changes of chlorophyll to pheophorbide and pheophytin (Schwimmer, 1981; Hamed, 1985). Lower chlorophyll content of solar drier was due to the activity of chlorophyllase enzyme that may be responsible for degradation of chlorophyll (Singh and Sagar, 2013). It was also observed that $\mathrm{T} 1$ had the highest antioxidant activity $(75.40 \%)$ while T2 had the lowest value (38.20\%), whereas fresh bitter melon had $45.50 \%$ antioxidant activity. It is difficult to summarize the evaluation of the antioxidant activity according to the conditions of heat processes. Decreases in phenol content do not lead systematically to a decrease of the antioxidant activity. The degradation products of phenolic compounds can also have an antioxidant activity sometimes higher than the initial phenolic compounds (Buchner et al., 2006; Murakami et al., 2004). Depending on the interactions occurring during heat processes, synergies between antioxidant compounds and the food matrix could occur (Wang et al., 2011). In some cases, the antioxidant capacity of flavonoids in a food matrix is enhanced (Freeman et al., 2010) while in other cases, the antioxidant capacity is reduced (Hidalgo et al., 2010).

Table (1): Chemical composition ${ }^{*}$ of fresh and dried bitter melons

\begin{tabular}{|c|c|c|c|}
\hline \multirow{2}{*}{ Constituents } & \multirow{2}{*}{$\begin{array}{c}\text { Fresh } \\
\text { bitter melon }\end{array}$} & \multicolumn{2}{|c|}{ Dried bitter melon } \\
\hline & & T1 & $\mathbf{T 2}$ \\
\hline Moisture \% & $92.84 \pm 0.0163$ & $8.40 \pm 0.0216$ & $8.09 \pm 0.0169$ \\
\hline Protein \% & $13.21 \pm 0.0162$ & $13.42 \pm 0.0124$ & $13.14 \pm 0.0081$ \\
\hline Crude fibers $\%$ & $1.47 \pm 0.0094$ & $1.42 \pm 0.0169$ & $1.39 \pm 0.0082$ \\
\hline Ash \% & $8.54 \pm 0.0216$ & $8.32 \pm 0.0094$ & $7.92 \pm 0.0169$ \\
\hline Total soluble solids (T.S.S) \% & $32.12 \pm 0.0161$ & $21.62 \pm 0.0047$ & $9.57 \pm 0.0159$ \\
\hline pH value & $4.64 \pm 0.0235$ & $4.88 \pm 0.0091$ & $5.42 \pm 0.0166$ \\
\hline Total acidity (as citric acid) & $2.91 \pm 0.0092$ & $3.07 \pm 0.0094$ & $1.81 \pm 0.0071$ \\
\hline Chlorophyll a (mg/100g) & $3.45 \pm 0.0309$ & $2.51 \pm 0.0216$ & $1.96 \pm 0.0201$ \\
\hline Chlorophyll b (mg/100g) & $2.93 \pm 0.0169$ & $2.35 \pm 0.0249$ & $1.78 \pm 0.0141$ \\
\hline Total carotenoids (mg/100g) & $2.32 \pm 0.0091$ & $2.17 \pm 0.0081$ & $1.46 \pm 0.0082$ \\
\hline Antioxidant activity $\%$ & $45.50 \pm 0.2054$ & $75.40 \pm 0.2943$ & $38.20 \pm 0.1247$ \\
\hline
\end{tabular}

\section{Mineral profile}

The mineral contents of fresh bitter melon and its treatments (T1 and T2) are presented in Table (2). Fresh bitter melon contained high levels of $\mathrm{K}, \mathrm{Ca}, \mathrm{Mg}, \mathrm{Mn}, \mathrm{Fe}$ and $\mathrm{Zn}$. A little decrease was observed in the aforementioned minerals after dried fresh bitter melon (T1) while clear decrement was observed after soaking and drying (T2) due to the loss of water soluble substances in water during the treatment to remove the bitter taste. Gopelan et al. (1993) found that mineral 
contents of bitter gourd were calcium (23.00), potassium (171.00), iron (2.00), manganese (0.08) and zinc $(0.46)$ as $\mathrm{mg} / 100 \mathrm{~g}$, while Kuri et al. (1991) reported that bitter melon contained 5.97, 119.92, 3.63 and $137.69 \mathrm{mg} / 100 \mathrm{~g}$ (on fresh weight basis) from Fe, $\mathrm{Mg}, \mathrm{Zn}$ and $\mathrm{Ca}$, respectively, while Bakare et al. (2010) found that the $\mathrm{Ca}, \mathrm{Mg}, \mathrm{K}, \mathrm{Fe}, \mathrm{Z}, \mathrm{Mn}$ contents in bitter melon were 2051.0, 255.0, 413.0, 98.0, 120.0, 156.0 $\mu \mathrm{g} / 100 \mathrm{~g}$, respectively. On the other hand, mineral contents of bitter gourd were 171.59, 22.78, 22.74, 0.45 and $72.45 \mathrm{mg} / 100 \mathrm{~g}$ from $\mathrm{K}, \mathrm{Ca}, \mathrm{Mn}, \mathrm{Fe}, \mathrm{Zn}$, respectively (Krishnendu and Nandini, 2016).

Table (2): Minerals contents ${ }^{*}$ of fresh bitter melon and its treatments

\begin{tabular}{|c|c|c|c|}
\hline \multirow{2}{*}{ Minerals (mg/100g) } & \multirow{2}{*}{$\begin{array}{c}\text { Fresh } \\
\text { bitter melon }\end{array}$} & \multicolumn{2}{|c|}{ Dried bitter melon } \\
\hline & & T1 & $\mathbf{T 2}$ \\
\hline Potassium (K) & $1439.22 \pm 0.014$ & $1426.11 \pm 0.005$ & $426.20 \pm 0.016$ \\
\hline Magnesium (Mg) & $427.21 \pm 0.012$ & $413.92 \pm 0.017$ & $162.60 \pm 0.020$ \\
\hline Calcium (Ca) & $511.98 \pm 0.013$ & $499.12 \pm 0.009$ & $212.90 \pm 0.021$ \\
\hline Manganese (Mn) & $0.79 \pm 0.004$ & $0.67 \pm 0.012$ & $0.60 \pm 0.017$ \\
\hline Iron ( Fe) & $4.32 \pm 0.016$ & $4.21 \pm 0.016$ & $3.92 \pm 0.024$ \\
\hline Zinc (Zn) & $1.37 \pm 0.017$ & $1.30 \pm 0.026$ & $1.31 \pm 0.022$ \\
\hline
\end{tabular}

Each value represents the average of three determinations \pm standard deviation

T1: Dried bitter melon with bitterness T2: Dried bitter melon without bitterness ${ }^{*}$ on dry weight basis

\section{Sugar profile of fresh and dried bitter melons}

Free sugar contents presented in Table (3), thirteen sugars were identified and fresh bitter melon had high levels of identified sugars, which reduced after drying. Sucrose, arabinose, glucose, tachyose, galacturonic, xylose and glucuronic of fresh bitter mellon were $21.84,19.83,14.06,13.39,11.61,10.89$ and $8.35 \mathrm{mg} / 100 \mathrm{~g}$, respectively. Concerning $\mathrm{T} 1$ and $\mathrm{T} 2$, drying of $\mathrm{T} 1$ resulted in a decrease in all sugars, while soaking then drying for T2 due to the flow of soluble substance in the water and cased a clear decrease in all identified sugars. The decrement could be attributed to the non-enzymatic browning between the free amino acids and reducing sugars (Reynolds, 1965). Therefore, the oven temperatures might have resulted in the loss of identified sugars.

Phenolic compounds of fresh and dried bitter melons

Table (4) shows the identification and concentration of 23 phenolic compounds in fresh and drying bitter melon. Pyrogallol was the major phenolic compounds in fresh bitter melon $(79.27 \mathrm{mg} / 100 \mathrm{~g})$ followed by benzoic acid $(75.99 \mathrm{mg} / 100)$, ellagic acid (28.63mg/100g), catechol (20.57 mg/100g), chlorogenic acid $(20.31 \mathrm{mg} / 100 \mathrm{~g}), 3,4,5$ methoxycinnamic acid $(16.51 \mathrm{mg} / 100 \mathrm{~g})$, ferulic acid $(15.88 \mathrm{mg} / 100)$ and alphacoumaric acid $(11.24 \mathrm{mg} / 100 \mathrm{~g})$, respectively. These results are agreement with Kubola and Siriamornpun (2011) and Horax et al. (2010).

The effect of drying (T1) and soaking then drying (T2) caused a decrement of the identified phenolic compounds. Decreasing and losing of phenolic compounds may be due to heating effect on the transformation of soluble tannins to condensed tannins
(Bate-Smith, 1977), and oxidation phenolic compounds to quinane (Khames, 2004).

Table (3): Sugar profile ${ }^{*}$ of fresh and dried bitter melons

\begin{tabular}{lccc}
\hline \multirow{2}{*}{$\begin{array}{c}\text { Sugar compounds } \\
(\mathbf{m g} / \mathbf{1 0 0 g})\end{array}$} & $\begin{array}{c}\text { Fresh } \\
\text { bitter } \\
\text { melon }\end{array}$ & \multicolumn{2}{c}{ Dried bitter melon } \\
\cline { 4 - 5 } Glucuronic & 8.35 & 7.44 & 1.43 \\
Stachyose & 13.39 & 11.81 & 2.54 \\
Galacturonic & 11.61 & 8.69 & - \\
Sucrose & 21.84 & 0.08 & 0.53 \\
Glucose & 14.06 & 9.58 & 1.01 \\
Xylose & 10.89 & 7.79 & 4.29 \\
Maltose & 23.25 & 0.08 & 0.57 \\
Fructose & 16.87 & 0.76 & 0.59 \\
Galactose & 1.41 & 0.67 & 0.22 \\
Mannose & 2.64 & 0.93 & 0.11 \\
Arabinose & 19.83 & 15.89 & 1.96 \\
Mannitol & 0.25 & 0.17 & 0.03 \\
Sorbitol & 0.35 & 0.10 & 0.02 \\
\hline T1: Died & & & \\
\hline
\end{tabular}

T1: Dried bitter melon with bitterness

T2: Dried bitter melon without bitterness

*on dry weight basis 
Table (4): Phenolic compounds ${ }^{*}$ of fresh and dried bitter melons

Phenolic compounds $(\mathrm{mg} / \mathbf{1 0 0 g})$
Fresh bitter melon
Dried bitter melon

T1

Gallic acid

Pyrogallol

4-Amino benzoic acid

Protocatchuic acid

Catechein

Chlorogenic acid

Catechol

Epi-catechin

Caffeine

$\rho-O H-b e n z o i c ~ a c i d$

Caffeic acid

Vanillic acid

$\rho$-Coumaric acid

Ferulic acid

Iso-Ferulic acid

Ellagic acid

e -Vanillic acid

Alpha-Coumaric acid

Benzoic acid

3,4,5 Methoxy Cinnamic acid

Coumarin

Salicylic acid

Cinnamic acid

\subsection{7 \\ 79.270}

1.550

11.700

4.637

20.310

20.570

5.810

2.960

3.128

1.564

7.989

5.503

15.88

2.053

28.630

23.180

11.240

75.990

16.510

5.601

11.480

0.335
1.667

39.730

0.105

3.901

0.712

7.892

6.902

1.798

0.908

0.645

0.491

2.503

1.942

8.534

0.845

0.152

19.572

3.202

17.410

16.26

10.157

3.357

31.635

9.651

9.544

2.588

0.479

1.449

3.534

0.131

0.592

6.625

0.054

1.829

0.148

2.679

1.898

1.322

0.297

0.316

0.404

2.056

0.276

-

\section{2}

T1: Dried bitter melon with bitterness

T2: Dried bitter melon without bitterness

*on dry weight basis

Flavonoid compounds of fresh and dried bitter melons

Flavonoid compounds are presented in Table (5). Acacetin was the major flavonoid compound (63.94 $\mathrm{mg} / 100 \mathrm{~g}$ ) in fresh bitter melon followed by quercetrin, rosmarinic, hisperidin, rutin, narengin and hspertin that had 54.46, 20.64, 13.14, 11.05, 8.41 and $5.64 \mathrm{mg} / 100 \mathrm{~g}$, respectively. On the other hand, drying (T1), soaking and drying (T2) led to a clear decrease in the levels of identified flavonoid compounds. These results are nearest with those reported by Kubola and
Siriamornpun (2011). The occurrence of those phenolic and flavonoid compounds in fresh bitter melon may enable to use these fruits as an interesting source of natural antioxidants for the food industry as well as an ingredient in suitable food products. Medicinal benefit of bitter melon has been attributed to its high antioxidant properties due in part to phenols, flavonoids, isoflavones, terpenes, anthroquinones and glucosinolates, all of which confer a bitter taste (Snee et al., 2011). 
Table (5): Flavonoid compounds ${ }^{*}$ of fresh and dried bitter melons

\begin{tabular}{lccc}
\hline $\begin{array}{l}\text { Flavonoid } \\
\text { compounds } \\
\text { (mg/100g) }\end{array}$ & $\begin{array}{l}\text { Fresh } \\
\text { bitter } \\
\text { melon }\end{array}$ & \multicolumn{2}{c}{ Dried bitter melon } \\
\cline { 4 - 5 } Narengin & 8.41 & 3.36 & 0.65 \\
Rutin & 11.05 & 7.17 & 2.25 \\
Hesperidin & 13.14 & 7.25 & 3.33 \\
Rosmarinic & 20.64 & 16.24 & 9.84 \\
Quercetrin & 54.46 & 31.02 & 19.14 \\
Quercetin & 0.46 & 0.29 & - \\
Hispertin & 5.64 & 1.55 & 0.41 \\
Kaempferol & 1.82 & 0.41 & 0.72 \\
Rhamnetin & 0.62 & 0.35 & 0.29 \\
Apigenin & 3.70 & 0.38 & 0.05 \\
Acacetin & 63.94 & 46.08 & - \\
\hline
\end{tabular}

T1: Dried bitter melon with bitterness

T2: Dried bitter melon without bitterness

*on dry weight basis
Vitamins profile of fresh and dried bitter melons

Table (6) shows that fresh bitter melon fruit had the highest levels of vitamin B3 and B12 (49.65 and $36.66 \mathrm{mg} / 100 \mathrm{~g}$ ) followed by B6, B2, B9 and B1 which recorded 28.25, 17.91, 17.33 and $12.05 \mathrm{mg} / 100 \mathrm{~g}$, respectively. After drying, a clear decrease was observed in all vitamins B complex were $6.44,7.96$, $37.19,15.08,9.26$ and $23.36 \mathrm{mg} / 100 \mathrm{~g}$ for vitamin $\mathrm{B} 1$, B2, B3, B6 ,B9 and B12, respectively. All vitamin B complex were reduced after soaking and drying (T2). Concerning vitamins A, D, E, and K (Table 6). Also, drying and soaking with drying treatments caused a pronounced reduction in the previous vitamins. Bitter melon is a powerful nutrient-dense plant composed of a complex array of beneficial compounds. These includes bioactive compounds, vitamins, minerals and antioxidants, which all contribute to their remarkable versatility in treating a wide range of illnesses (Bakare et al., 2010), on the other hand, the fruits contains high amounts of vitamins C, A, E, B1, B2 and B3, as well as vitamin B9 (folate). USDA-ARS (2015) reported that bitter melon content were $0.051,0.053,0.041,0.14$ $\mathrm{mg} / 100 \mathrm{~g}$ and $6,4.8 \mu \mathrm{g} / 100 \mathrm{~g}$ of B1, B2, B6, E and $\mathrm{K}, \mathrm{A}$, respectively.

Table (6): Vitamins profile ${ }^{*}$ of fresh and dried bitter melons

\begin{tabular}{lllll}
\hline \multirow{2}{*}{ Vitamins (mg/100g) } & & Fresh & \multicolumn{2}{c}{ Dried bitter melon } \\
\cline { 3 - 4 } & & Thitter melon & T1 & 3.117 \\
\cline { 3 - 4 } & Riboflavin (B2) & 12.05 & 6.44 & 4.514 \\
& Nicotinic acid (B3) & 17.91 & 7.96 & 22.51 \\
Vit. B complex & Pyridoxine ( B6) & 49.65 & 37.19 & 10.24 \\
Group & Folic acid (B9) & 28.25 & 15.08 & 1.851 \\
& Cobalamin (B12) & 17.33 & 9.26 & 11.47 \\
Vit. A & & 36.66 & 23.36 & 0.062 \\
Vit. D & & 0.319 & 0.118 & 0.002 \\
Vit. E & & 0.035 & 0.016 & 0.011 \\
Vit. K & & 0.088 & 0.023 & 0.472 \\
\hline
\end{tabular}

T1: Dried bitter melon with bitterness T2: Dried bitter melon without bitterness on dry weight basis

Cytotoxic activity of fresh and dried bitter melons

The cytotoxic activity of fresh and dried bitter melon fruit on tumor human lung cells (A549) were shown in Table (7) and Figs (1, 2 and 3). The results showed that the incubation of lung cell (A549) with different level of fresh and dried bitter melon extract $(0.00$ to $100 \mu \mathrm{g} / \mathrm{ml})$ for $48 \mathrm{~h}$. at $37^{\circ} \mathrm{C}$ in atmosphere of $5 \% \mathrm{CO}_{2}$ reduced the viability of this cell.

A high cytotoxic effect of fresh bitter melon extract $\quad(49.3 \mu \mathrm{g} / \mathrm{ml})$ was observed using pharmacological dose which reduced the survival of the human lung carcinoma cell line (A549) to 50\% (50\% inhibition) followed by dried bitter melon extract (T1)
(95 $\mu \mathrm{g} / \mathrm{ml}$ ). On the other hand, treatment (T2) did not show any cytotoxicity as concluded from the $\mathrm{IC}_{50}$ values as shown in Table (7) and Fig (3). This may be due to the removing of momoridicine alkaloid and charantin during soaking which responsible for bitterness of bitter melon. Medical activity of bitter melon has been attributed to its high antioxidant properties due in part to phenols, flavonoids, isoflavones, terpenes, anthroquinones and glucosinolates, all of which confer a bitter taste (Drewnowski and Gomez-Carneros, 2000). Removal of active bitter components through a variety of debitterning processes as well as selective breeding can result in loss of possible health benefits. 
From the previous results, it could be clearly concluded that fresh bitter melon showed a good cytotoxic effect against lung cancer cells (A549) followed by dried bitter melon, due to their phenolic and flavonoid compounds (Table 7 and Figs 1, 2, 3). The diet of bitter melon can be used as a preventive/therapeutic agent for prostate, breast, colon and adrenocortical cancers (Ray et al., 2010; Ru et al., 2011; Brennan et al., 2012; Kwatra et al., 2013). Therefore, bitter melon might have health benefits for consumers as a potential functional food.

Table (7): Cytotoxic activity of fresh and dried bitter melons against human lung cells (A549)

\begin{tabular}{|c|c|c|c|c|c|c|c|}
\hline \multirow{2}{*}{\multicolumn{2}{|c|}{ Treatments }} & \multicolumn{5}{|c|}{ Concentration ( $\mu \mathrm{g} / \mathrm{ml})$} & \multirow{2}{*}{$\frac{\mathrm{IC}_{50}{ }^{*}}{(\mu \mathrm{g} / \mathrm{ml})}$} \\
\hline & & 0 & 12.5 & 25 & 50 & 100 & \\
\hline \multicolumn{2}{|c|}{ Fresh bitter melon } & 1.000 & 0.850 & 0.700 & 0.500 & 0.350 & 49.3 \\
\hline \multirow{2}{*}{$\begin{array}{l}\text { Dried bitter } \\
\text { melon }\end{array}$} & $\mathbf{T 1}$ & 1.000 & 0.930 & 0.825 & 0.600 & 0.496 & 95 \\
\hline & $\mathbf{T} 2$ & 1.000 & 1.000 & 0.925 & 0.710 & 0.550 & - \\
\hline
\end{tabular}

$\mathrm{IC}_{50}$ : Dose, which reduces survival to $50 \% ; \quad$ T1: Dried bitter melon with bitterness; $\quad$ T2: Dried bitter melon without bitterness

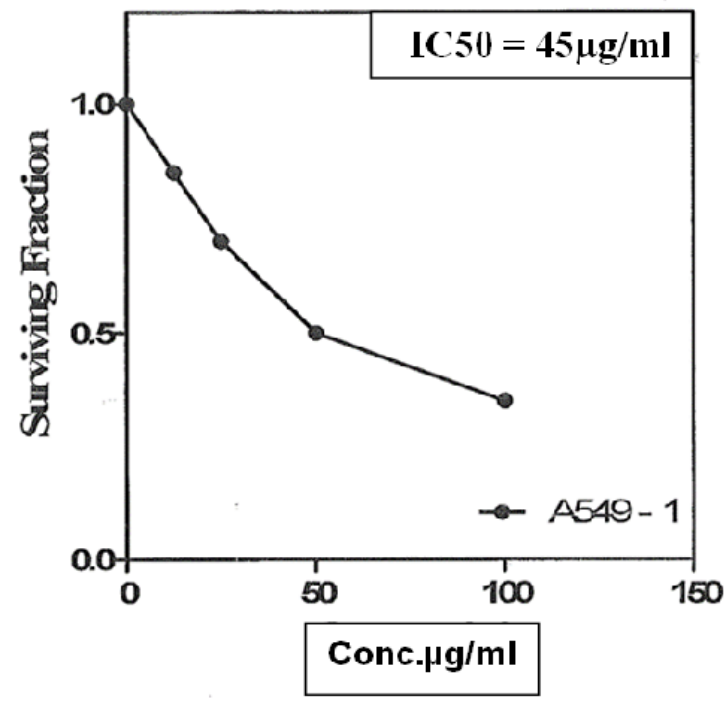

Fig. (1): Cytotoxic activity of fresh bitter melon against human lung cells (A549)

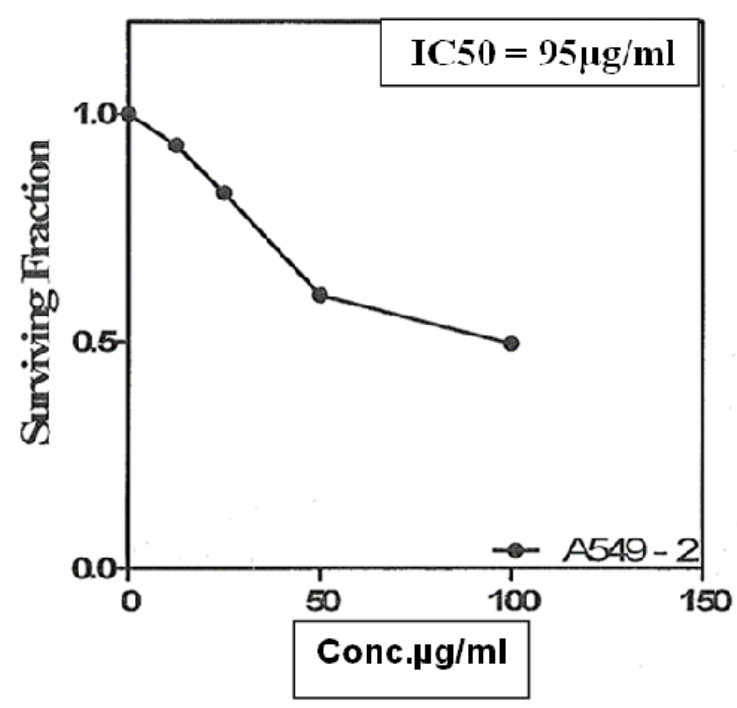

Fig. (2): Cytotoxic activity of dried bitter melon against human lung cells (A549)

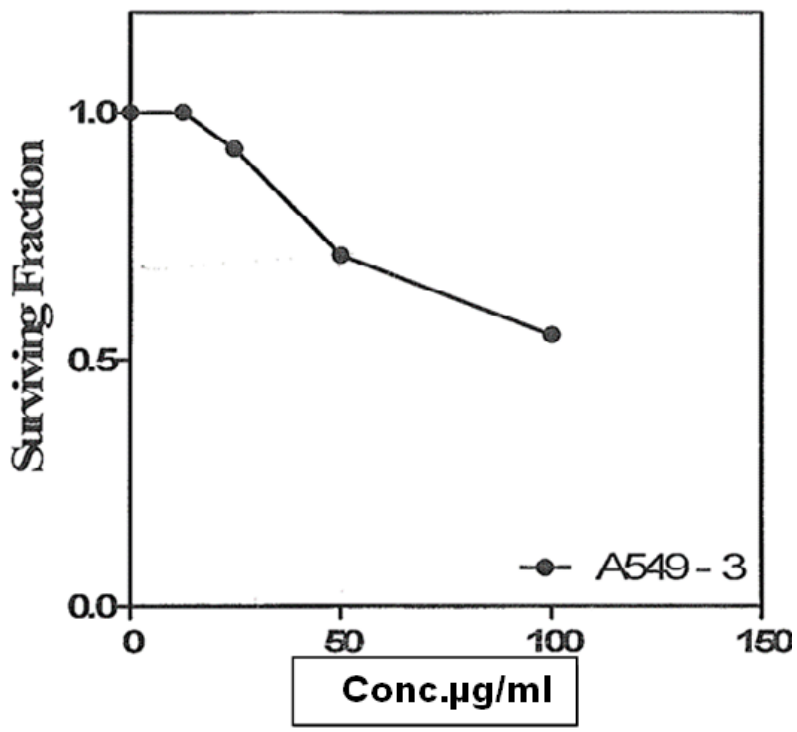

Fig. (3): Cytotoxic activity of dried bitter melon after removal of bitterness against human lung cells (A549) 


\section{Sensory evaluation of bitter melon drinks}

The sensory evaluation of bitter melon drinks are shown in Table (8). Drink (BT3) for T1 had the highest mean value of color, taste, odor and overall palatability, while drink (BT5 and control) for T1 had the lowest mean value of all sensory attributes. A significant difference was observed. On the other hand, non significant differences were observed in sensory attributes of bitterness in bitter melon drinks with all percentage of tea additive. Concerning the prepared drinks with spearmint powder, results in Table (8) showed that drink processed from $\mathrm{T} 1$ and spearmint (BS3) had the highest values of color, taste, odor and overall palatability, while drinks (the control and BS5) for $\mathrm{T} 1 \mathrm{had}$ the lowest value of all sensory attributes. Meanwhile, all the drinks prepared from dried bitter melon without bitterness and spearmint appeared accepted by the panelists, while a significant difference was observed between all processed drinks and (BS1 and BS5) in the color, also in the taste of control and BS5. The drinks of bitter melon: black tea or spearmint (BT3) for T1 at the ratio of 1:3 was found to be highly acceptable. The other variations in which the ratios of bitter melon to tea (powder) were increased led to lower scores in parameters like odor and taste.

Table (8): Sensory evaluation of dried bitter melon drinks

Drink (dried bitter melon with black tea)

\begin{tabular}{lcccccccc}
\cline { 2 - 8 } $\begin{array}{c}\text { Treatment } \\
\text { No. }\end{array}$ & \multicolumn{2}{c}{ T1 (Dried bitter melon with bitterness) } & \multicolumn{3}{c}{ T2 (Dried bitter melon without bitterness) } \\
\cline { 2 - 8 } & $\begin{array}{c}\text { Color } \\
(\mathbf{1 0 )}\end{array}$ & $\begin{array}{c}\text { Taste } \\
\mathbf{( 1 0 )}\end{array}$ & $\begin{array}{c}\text { Odor } \\
\mathbf{( 1 0 )}\end{array}$ & $\begin{array}{c}\text { Overall } \\
\text { Palatability } \\
(\mathbf{1 0 )}\end{array}$ & $\begin{array}{c}\text { Color } \\
(\mathbf{1 0 )}\end{array}$ & $\begin{array}{c}\text { Taste } \\
(\mathbf{1 0 )}\end{array}$ & $\begin{array}{c}\text { Odor } \\
(\mathbf{1 0})\end{array}$ & $\begin{array}{c}\text { Overall } \\
\text { Palatability } \\
(\mathbf{1 0})\end{array}$ \\
\hline Control & $6.7^{\mathrm{e}}$ & $5.2^{\mathrm{d}}$ & $6.1^{\mathrm{d}}$ & $5.9^{\mathrm{c}}$ & $7.4^{\mathrm{a}}$ & $6.8^{\mathrm{b}}$ & $7.1^{\mathrm{a}}$ & $6.7^{\mathrm{a}}$ \\
BT1 & $7.9^{\mathrm{bc}}$ & $6.7^{\mathrm{bc}}$ & $6.9^{\mathrm{bc}}$ & $7.1^{\mathrm{b}}$ & $8.1^{\mathrm{a}}$ & $7.8^{\mathrm{a}}$ & $7.7^{\mathrm{a}}$ & $7.3^{\mathrm{a}}$ \\
BT2 & $7.9^{\mathrm{b}}$ & $7.3^{\mathrm{ab}}$ & $7.6^{\mathrm{ab}}$ & $7.8^{\mathrm{a}}$ & $8.3^{\mathrm{a}}$ & $8.2^{\mathrm{a}}$ & $7.8^{\mathrm{a}}$ & $7.9^{\mathrm{a}}$ \\
BT3 & $8.7^{\mathrm{a}}$ & $7.8^{\mathrm{a}}$ & $7.8^{\mathrm{a}}$ & $8.1^{\mathrm{a}}$ & $8.4^{\mathrm{a}}$ & $8.4^{\mathrm{a}}$ & $8.4^{\mathrm{a}}$ & $8.5^{\mathrm{a}}$ \\
BT4 & $7.4^{\mathrm{cd}}$ & $6.2^{\mathrm{c}}$ & $6.5^{\mathrm{cd}}$ & $7.0^{\mathrm{b}}$ & $8.4^{\mathrm{ab}}$ & $7.7^{\mathrm{ab}}$ & $8.1^{\mathrm{a}}$ & $8.2^{\mathrm{a}}$ \\
BT5 & $7.2 \mathrm{~d}^{\mathrm{e}}$ & $5.1^{\mathrm{d}}$ & $6.2^{\mathrm{d}}$ & $6.1^{\mathrm{c}}$ & $7.9^{\mathrm{ab}}$ & $8.2^{\mathrm{a}}$ & $7.9^{\mathrm{a}}$ & $7.3^{\mathrm{a}}$ \\
LSD at 0.05 & 0.576 & 0.641 & 0.638 & 0.630 & 1.431 & 1.656 & 1.559 & 1.367 \\
\hline
\end{tabular}

Drink (dried bitter melon with spearmint powder)

\begin{tabular}{lcccccccc}
\hline Control & $6.7^{\mathrm{d}}$ & $5.2^{\mathrm{d}}$ & $6.1^{\mathrm{d}}$ & $5.9^{\mathrm{e}}$ & $7.4^{\mathrm{a}}$ & $6.8^{\mathrm{b}}$ & $7.1^{\mathrm{a}}$ & $6.7^{\mathrm{a}}$ \\
BS1 & $7.9^{\mathrm{c}}$ & $6.8^{\mathrm{b}}$ & $7.2^{\mathrm{c}}$ & $7.3^{\mathrm{c}}$ & $8.4^{\mathrm{ab}}$ & $7.7^{\mathrm{ab}}$ & $8.1^{\mathrm{a}}$ & $8.2^{\mathrm{a}}$ \\
BS2 & $8.7^{\mathrm{ab}}$ & $7.6^{\mathrm{a}}$ & $7.9^{\mathrm{b}}$ & $7.9^{\mathrm{b}}$ & $8.4^{\mathrm{a}}$ & $8.4^{\mathrm{a}}$ & $8.4^{\mathrm{a}}$ & $8.5^{\mathrm{a}}$ \\
BS3 & $9.0^{\mathrm{a}}$ & $8.1^{\mathrm{a}}$ & $8.5^{\mathrm{a}}$ & $8.6^{\mathrm{a}}$ & $8.6^{\mathrm{a}}$ & $8.6^{\mathrm{a}}$ & $8.7^{\mathrm{a}}$ & $8.4^{\mathrm{a}}$ \\
BS4 & $8.5^{\mathrm{b}}$ & $6.3^{\mathrm{bc}}$ & $6.8^{\mathrm{c}}$ & $7.2^{\mathrm{cd}}$ & $8.3^{\mathrm{a}}$ & $8.4^{\mathrm{a}}$ & $8.2^{\mathrm{a}}$ & $7.9^{\mathrm{a}}$ \\
BS5 & $7.9 \mathrm{c}$ & $5.9^{\mathrm{c}}$ & $6.7^{\mathrm{cd}}$ & $6.7^{\mathrm{d}}$ & $7.9^{\mathrm{ab}}$ & $7.8 \mathrm{a}$ & $7.7^{\mathrm{a}}$ & $7.7^{\mathrm{a}}$ \\
LSD at 0.05 & 0.4 & 0.674 & 0.566 & 0.512 & 1.431 & 1.656 & 1.559 & 1.367 \\
\hline
\end{tabular}

Value with different letters in the same column are significantly different at $\mathrm{P}<0.05$

Control: bitter melon powder

BT1: bitter melon powder + black tea $(1+1)$

BT2: bitter melon powder + black tea $(1+2)$

BT3: bitter melon powder + black tea $(1+3)$

BT4: bitter melon powder + black tea $(2+1)$

BT5: bitter melon powder + black tea $(3+1)$
BS1: bitter melon powder + spearmint powder $(1+1)$

BS2: bitter melon powder + spearmint powder $(1+2)$

BS3: bitter melon powder + spearmint powder $(1+3)$

BS4: bitter melon powder + spearmint powder $(2+1)$

BS5: bitter melon powder + spearmint powder $(3+1)$ 


\section{CONCLUSION}

The use of fresh and dried bitter melons as excellent sources for natural bioactive components, natural antioxidant and vitamins. This can lead to application in food products and dietary supplements. These natural plant compounds can be beneficial for human health. Results showed that fresh and dried bitter melons were rich in protein, mineral elements and antioxidant contents. Sucrose, arabinose, glucose and stachyose were the major identified sugars in fresh bitter melon, e-vanillic acid, pyrogallol and benzoic acid also quercitrin, rosmarinic acid and hisperidin were the main phenolic and flavonoid compounds, vitamin B12, B3, $\mathrm{B} 6$, B9 and $\mathrm{k}$ represented high values in fresh bitter melon. Drying led to a clear decrease in all previous compounds. Also, the removal of the bitterness from bitter melon fruit led to a high decrease in all components. The $\mathrm{IC}_{50}$ of fresh and dried bitter melon extract showed a good cytotoxic effect against lung cancer cells (A549) while dried bitter melon free from bitterness did not show any effect. Therefore, when using bitter melon in feeding one should not remove the bitterness from it.

\section{REFERENCES}

AOAC (2010). Association of official Analytical chemists international. Official Methods of Analysis, $19^{\text {th }}$ ed. Washington, D C, U S A.

Ataman, J. E., D.B. Grillo, E. K. I. Omangbai, F. M. Amaechina, V. Okonjii and B. A. Avinde (2006). Chemical composition and quantitative elemental investigation of bitter melon. Med. Sci., 6(5): 828-832.

Bakare, R. I., Magbagbeola, O. A., Akinwande, A. I. and O. W. Okunowo (2010). Nutritional and chemical evaluation of Momordica charantia. J. Med. Plant Res., 4(21): 2189 2193.

Basch, E., S. Gabardi and C. Ulbricht (2003). Bitter melon (Momordica charantia): A review of efficacy and safety. Am. J. of Health-System Phar., (60): 199-204.

Bate-Smith, E. C. (1977). Astringent tannins of acer species. Phytochem., 16: 1421.

Brennan,V. C., C. M. Wang and W. H. Yang (2012). Bitter melon (Momordica charantia) extract suppresses adrenocortical cancer cell proliferation through modulation of the apoptotic pathway, steroidogenesis, and insulin-like growth factor type1 receptor/RAC$\alpha$ serine/threonine-protein kinase signaling. J. Med. Food, 15: 325-334.

Buchner, N., A. Krumbein, S. Rhon and L. W. Kroh (2006). Effect of thermal processing on the flavonols rutin and quercetin. Rapid Commun. Mass Spectrom., 20: 3229-3235.

Chinnici, F., U. Spinabelli, C. Riponi and A. Amati (2005). Optimization of the determination of organic acids and sugars in fruit juices by ionexclusion liquid chromatography. Journal of Food Composition and Analysis, 18: 121-130.
Dandawate, P. R., D. Subramaniam, S. B. Padhye and S. Anant (2016). Bitter melon: a panacea for inflammation and cancer. Chin J. Nat. Med., 14(2): 81-100.

Drewnowski, A. and C. Gomez-Carneros (2000). Bitter taste, phytonutrients, and the consumer: A review. Am. J. Clin. Nutr., 72: 1424-1435.

Freeman, B. L., D. L. Eggett and T. L. Parke (2010). Synergistic and antagonistic interactions of phenolic compounds found in navel oranges. J. Food. Sci., 75: 570-576.

Gfimiz-Gracia, M. M., M. D. Jim6nez-Carmona and C. Luque-de (2000). Determination of vitamins D2 and D3 in pharmaceuticals by supercriticalfluid extraction and HPLC separation with UV Detection. Chromatographic, 51: 7-8.

Gopelan, C., B. V. Rama Sastri and S. C. Balalsubramnnian (1993). Nutritive value of Indian foods, 2nd ed. Hyderabad: National Institute of Nutrition, IGMR. Cited from Bitter Gourd: Botany, Horticulture, Breeding. TusarK. Behera, Snigdha Behera, and L. K. Bharathi (eds.). Indian Agricultural Research Institute New Delhi, 110012, India.

Hamed, H. S. (1985). Studies on utilization of some cannery wastes (Carotenoids of orange flavedo).Ph. D. Thesis. Fac. of Agr. Cairo University.

Hidalgo, M., C. M. Sanchez, D. Pascual and S. Teresa (2010). Flavonoid-flavonoid interaction and its effect on their antioxidant activity Food Chem., 121: 691-696.

Horax, R., N. Hettiarachchy and P. Chen (2010). Extraction, quantification, and antioxidant activities of phenolics from pericarp and seeds of bitter melons (Momordica charantia) harvested at three maturity stages (immature, mature, and ripe). J. Agric. Food Chem., 7: 4428-33.

Islam, S., M. Jalaluddin and N. S. Hettiarachchy (2011). Bioactive compounds of bitter melon genotypes (Momordica charantia L.) in relation to their physiological functions. Funk. Foods Health Dis., 2 (11): 61-74.

Khan, A. and R. Anderson (2003). Insulins Potentiating Factor (IPF) present in foods, Spices and natural products. Pak. J. Nutr., 2(4): 254-257.

Khames, M. S. (2004). Biochemical and technological studies on some natural phenolic compound as antioxidant. Ph.D. Thesis, Faculty of Agric., Cairo Univ., Egypt.

Krawinkel, M. B. and G. B. Keding (2014). Bitter Gourd (Momordica charantia L.): A dietary approach to hyperglycemia. Nutrition Reviews, 64(7): 331-7.

Krishnendu, J. R. and P. V. Nandini (2016). Nutritional composition of bitter gourd types (Momordica charantia L.). International Journal of Advanced Engineering Research and Science, (3): 96-103.

Kubola, J. and S. Siriamornpun (2011). Phytochemicals and antioxidant activity of different fruit fractions (peel, pulp, aril and seed) of Thai gas 
(Momordica cochinchinensis Spreng). Food Chemistry, 127(3, 1): 1138-1145.

Kubola, J. and S. Siriamornpun (2008). Phenolic contents and antioxidant activities of bitter gourd (Momordica charantia L.) leaf, stem and fruit fraction extracts in vitro. Food Chemistry, 110(4): 881-890.

Kulkarni, A. S., H. B. Patil and C. G. Mundada (2005). Studies on effect of pretreatment on quality of dehydrated bitter gourd. Journal of Engineering, 2: 31-33.

Kuri, E., K. Yuwa, R. Sundar, K. Chalapan, P. Gwyn and E. Donaid (1991). Chemical composition of Momordica charantia L. fruits. J. Agric. Food Chem., 39: 1762-1763.

Kwatra, D., D. Subramaniam and P. Ramamoorthy (2013). Methanolic extracts of bitter melon inhibit colon cancer stem cells by affecting energy homeostasis and autophagy. EvidBased Compl Alt Med., http://dx. doi.org/10.1155/2013/702869

Lee, J. Y., H. J. Park, C. Y. Lee and W. Y. Choi (2003). Extending shelf-life of minimally processed apples with edible coatings and antibrowning agents. Lebensm.-Wiss. U. - Technol., 36: 323329.

Murakami, M., T. Yamaguchi, H. Takamura and T. Matoba (2004). Effects of thermal treatment on radical-scavenging activity of single and mixed polyphenolic compounds. Food Chem., 69: 710.

Pascale, G., H. Mireille, B. Patrick and J. Marie (1999). Antioxidant composition and activity of barley (Hordeum vulgare) and malt extracts of isolated phenolic compounds. Journal of the Science of Food and Agriculture, 79: 16251634.

Papadoyannis, I. N., G. K. Tsioni and V. F. Samanidou (1997). Simultaneous determination of nine water and fat-soluble vitamins after separation and RP-HPLC analysis in pharmaceutical preparations and biological fluids. Journal of liquid Chromatography and Related Technologies, 20: 3203-3231.

Pirjo, M., A. Jouni and K. Jorma (2000). Determination of flavonoids in plant material by HPLC with diode-array and electro-array detections. Journal of Agricultural and Food Chemistry, 48: 5834-5841.

Pyka, A. and J. Sliwiok (2001). Chromatographic separation of tocopherols. Journal of Chromatography A, 935(1-2): 71-76.

Raghuramulu, N., K. Madhavan-Nair and S. Kalyanasundaram (1983). Manual of laboratory techniques. National Institute of Nutrition. Hyderabad, India, 42.

Ray, R.B., A. Raychoudhuri and R. Steele (2010). Bitter melon (Momordica charantia L.) extract inhibits breast cancer cell proliferation by modulating cell cycle regulatory genes and promotes apoptosis. Cancer Res., 70: 19251931.
Reynolds, T. M. (1965). Chemistry of non- enzymatic browning. Advances in Food Research, 14:299.

RSC, Royal Society of Chemistry (2003). "How to make a perfect cup of tea". Archived from the original on (2014), 8:11.

Ru, P., R. Steele and P. V. Nerurkar (2011). Bitter melon extract impairs prostate cancer cellcycle progression and delays prostatic intraepithelial neoplasia in TRAMP model. Cancer Prev. Res., 4: 2122-2130.

Schwimmer, S. (1981). Source book of food enzymology. The AVI Publishing Comp., Inc., Westport, Connecticut, USA.

Shahidul, I., J. Mohammad and S. H. Navam (2011). Bioactive compounds of bitter melon genotypes (Momordica charantia L.) in relation to their physiological functions. Functional Foods in Heals and Disease, 2: 61-74.

Sheela, S. and K. Sruthi (2014). Evaluation of acceptability, nutrient content, antimicrobial activity and storage stability of formulated bitter gourd: Mosambi and bitter gourd: lemon RTS beverages. Int. J. Curr. Microbiol. App. Sci., 3(6): 25-31

Sheng, S. M. N. and J. L. Silva (2006). Antioxidant activity, anthocyanins, and phenolic of rabbit eye blueberry (Vaccinium ashei) by-products as affected by fermentation. Food Chemistry, 97(3): 447-451.

Singh, U. and V. R. Sagar (2013). Effect of drying methods on nutritional compostion of dehydrated bitter gourd (Momordica Charantia L.) Rings. Agriculture for sustainable development, 1(1): 83-86.

Skehan, P., R. Storeng, D. Scudiero and D. Vistica (1990). New colorimetric cytotoxicity assay for anti-cancer drug screening. J. Natl. Cancer. Inst., 82 (13): 1107-1112.

Snee, L. S., V. R. Nerurkar, D. A. Dooley, J. T. Efird, A. C. Shovic and P. V. Nerurkar (2011). Strategies to improve palatability and increase consumption intentions for Momordica charantia L. (bitter melon): A vegetable commonly used for diabetes management. Nutr. J., 10: 78

Snedecor, G. W. and W. G. Cochran (1980). "Statistical Methodes" $7^{\text {th }}$ ed. lowa.

Tomas, P., C. Ruiz, M. Martınez-Lozano, G. Dolores and M. Jesus (2007). High-performance liquid chromatography-photochemical reduction in aerobic conditions for determination of $\mathrm{K}$ vitamins using fluorescence detection. Journal of Chromatography A, 1141: 67-72.

USDA-ARS (2015). National Nutrient Database for Standard Reference Release 28, Full Report (All Nutrients) 11025, Balsam-pear (bitter gourd), pods, cooked, boiled, drained, without salt.

Verma, V. N. (2015). Chemical composition and quantitative elemental investigation of bitter melon. Department of Chemistry, Faculty of Natural Sciences, University of Guyana, 16: 84-94. 
Wang, S., K. A. Meckling, M. F. Marcone, Y. Kakuda and R. Tsao (2011). Synergistic, additive, and antagonistic effects of food mixtures on total antioxidant capacities. J. Agric. Food Chem., 59: 960-968.

Yuwai, K. E., K. S. Rao, C. Kaluwin, P. G. Jones and D. E. Rivett (1991). Chemical composition of
Momordica charantia L. fruits. J. Agric. Food Chem., 39(10): 1762-1763.

Zhu, Y., Y. Dong and X. W. Qian (2012). Effect of superfine grinding on antidiabetic activity of bitter melon powder. Int. J. Mol. Sci., 13: 14203-14218.

\section{القيمة الغذائية وتحسين قابلية الشمام المر الثر

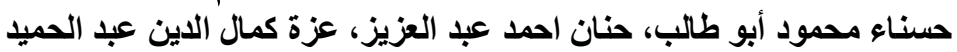

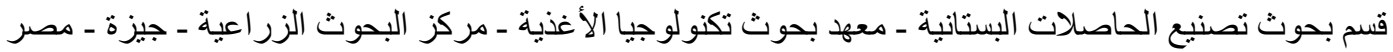

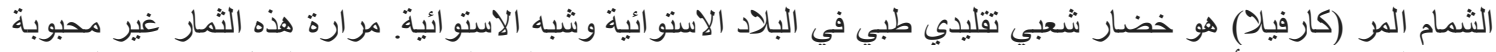

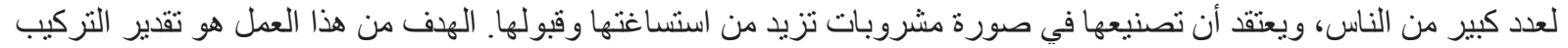

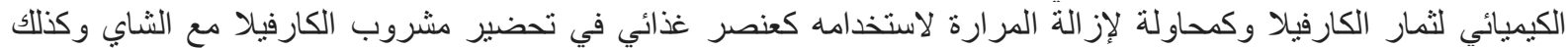

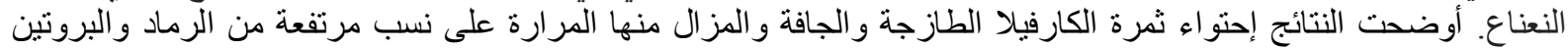

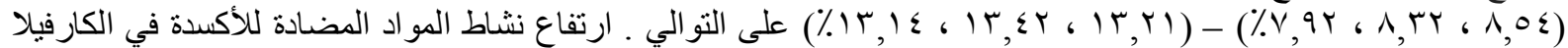

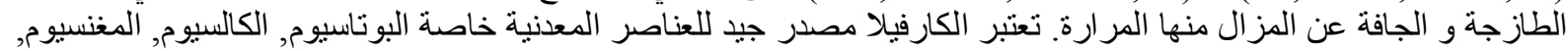

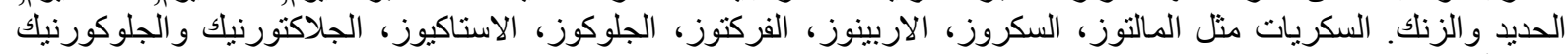

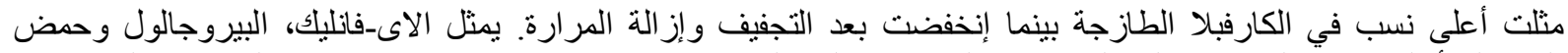

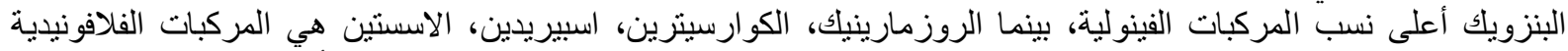

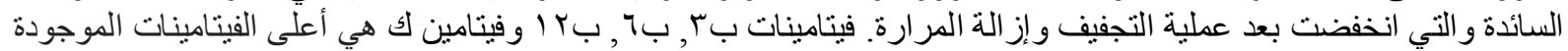

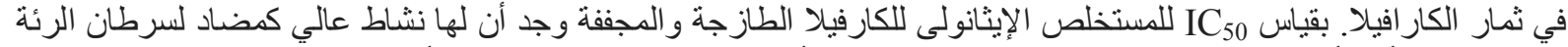

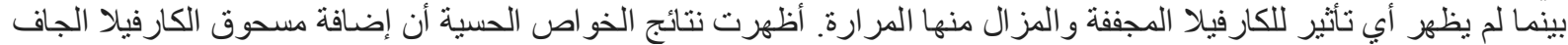

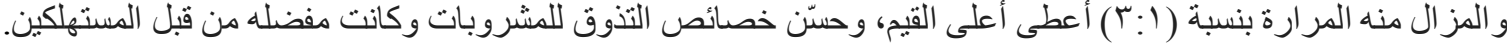

